\title{
Mechanism of Damage of Ferritic Ductile Iron, Influence of Matrix Heterogeneity
}

\author{
Diego O. Fernandino ${ }^{a}$, Roberto E. Boeri ${ }^{b *}$ and Juan M. Massone ${ }^{c}$ \\ INTEMA, Universidad Nacional de Mar del Plata-CONICET, Av. Colón 10850, Mar del Plata, \\ B7606BVZ, Argentina \\ adfernandino@fi.mdp.edu.ar, bboeri@fi.mdp.edu.ar, 'cmassonej@fi.mdp.edu.ar
}

Keywords: Ductile cast iron, damage mechanism, mechanical properties, indentation.

\begin{abstract}
Ferritic ductile cast iron (FDI) microstructure is composed by graphite nodules embedded in a ferritic matrix. It is usual to assume that the ferritic matrix is homogeneous. However, the experimental analysis shows impurities and in some cases a high degree of heterogeneity. It is necessary to investigate the influence of these heterogeneities on the mechanical properties of FDI. This work focusses on the characterization of the elastoplastic properties of different zones of the ferritic matrix of FDI and the identification of the sequence and extent of the damage mechanisms at the micro-scale under uniaxial tensile loading.

The methodologies for the characterization of the material micro constituents and microsegregated zones involve nano-indentation and atomic force microscopy techniques in combination with computational modelling. The analysis is performed by applying inverse analysis algorithms proposed in the literature. The microsegregated zones are identified by using color etching. The assessment of the micro-scale damage mechanisms was performed by in-situ optical microscopy observation of tensile tests of very small specimens.

The results led to the quantification of the differences in mechanical properties along the metallic matrix as a result of the existing heterogeneities and allow for a better understanding of the ductile iron damage mechanism.
\end{abstract}

\section{Introduction}

Ferritic ductile cast iron (FDI) microstructure is composed by graphite nodules embedded in a ferritic matrix. It can be obtained as-cast or by an annealing heat treatment cycle [1]. FDI is usually used when ductility and good impact properties are required, such as in marine applications, valves, fittings, truck and agricultural implements and automotive steering knuckles.

During the solidification process of ductile cast irons (DI), graphite and austenite nucleate and grow in the liquid, with the austenite growing dendritically. The first to freeze zones, coincident with the axes and arms of the austenite dendrites, are usually named FTF. As the solid phases grow and collide with neighboring growing units, the last portions of remaining melt locate between them, and are referred to as the Last To Freeze zones (LTF) [2,3]. Certain alloy elements and impurities may diffuse and concentrate or be depleted in these zones. In addition, the natural volume change associated to solidification can induce the formation of small shrinkage cavities at the LTF [3]. In spite that the experimental evidence shows impurities and a high degree of heterogeneity in the matrix [3-6], it is usual to assume that the ferritic matrix is homogeneous, Rivera et. al [3] evaluated the effectiveness of several metallographic techniques and showed that a color reagent sensitive to microsegregation provides the best results to reveal the solidification structure of DI.

In this context, the assessment of the influence of the metallic matrix heterogeneity on the mechanical properties needs experimental analysis at the microstructural level. Instrumented indentation techniques are identified as a useful tool to characterize the mechanical properties, however, the literature reports the possibility of finding more than one elastic-plastic solid that essentially exhibits the same contact behavior, i.e. the same load $(\mathrm{P})$ vs penetration $(\mathrm{h})$ curve. In consequence, several aspects related to the uniqueness of the solution provided by inverse methods 
were discussed by different authors [7-12]. For example, Mata et al. [14] developed mathematical formulations to relate the hardness and pile-up or sinking-in phenomenon around sharp indentations with the elastic-plastic mechanical properties by using the results retrieved from instrumented indentation test and atomic force microscopy (from now on "methodology A"). However, the values retrieved from their inverse analysis seem to be very sensitive to the dispersion of the experimental results.

The present investigation is focused on the characterization of the elastic-plastic properties of different zones of the ferritic matrix of FDI and the identification of the sequence and extent of the damage mechanisms at the micro-scale under uniaxial tensile tests. The methodology for the characterization of the material micro constituents and micro-segregated zones is based on nanoindentation and atomic force microscopy techniques in combination with computational modelling. The analysis is performed by applying a modified version of an inverse analysis algorithm proposed in the literature (from now on "methodology B"). The microsegregated zones are identified by using color etching. The assessment of the micro-scale damage mechanisms was performed by insitu optical microscopy observation of very-small tensile test specimens.

\section{Materials and Methods}

\section{Materials}

The DI samples were provided by MEGAFUND S.A. The chemical composition was determined by means of a Baird DV6 spectrometer. The chemical composition is listed in Table 1. The samples were one-inch ' $\mathrm{Y}$ ' blocks cast in sand molds (ASTM A897M). All blocks were ferritized by an annealing heat treatment, consisting of an austenitizing stage at $920^{\circ} \mathrm{C}$ for $4 \mathrm{~h}$, followed by a slow cooling down $\left(55^{\circ} \mathrm{C}\right.$ per hour) to room temperature inside the furnace. Metallographic samples were prepared by standard polishing and etching methods using nital $(2 \%)$ and a color etchant reagent declared to be sensitive to the segregation of $\mathrm{Si}(10 \mathrm{~g} \mathrm{NaOH}, 40 \mathrm{gKOH}, 10 \mathrm{gr}$ picric acid and $50 \mathrm{ml}$ distilled water). Following the experimental procedures reported in Rivera et al. [3], the colour etchant was used at $120^{\circ} \mathrm{C}$ (boiling temperature)

The microstructure was characterized by using an optical microscope OLYMPUS PMG3 and the Image Pro-Plus software. The results of as-cast characterization are listed in Table 2. The nodularity was considered suitable for this study.

Fig. 1 shows the as cast and after annealing microstructure. Fig. 1a shows a fully pearlitic microstructure as-cast while Fig. 1b shows the fully ferritic microstructure after annealing. Fig. 1c shows the microsegregation zones (FTF and LTF) after color etching.

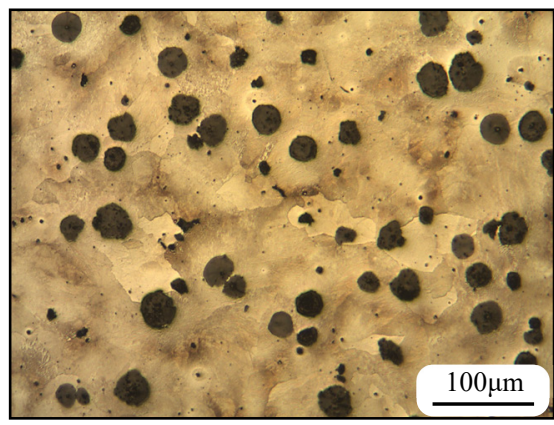

(a)

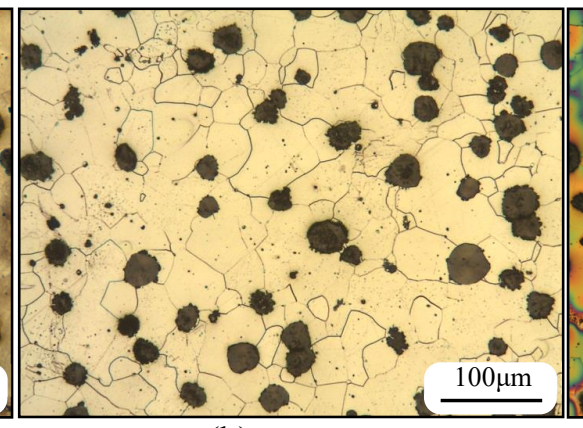

(b)

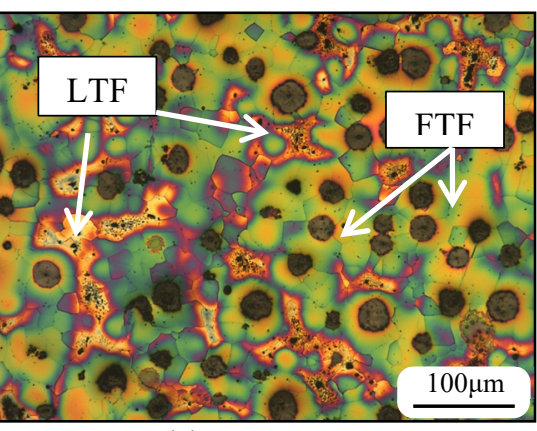

(c)

Figure 1. Optical micrographies; (a) As-cast condition etched with Nital 2\%, (b) annealing condition etched with Nital 2\%, (c) annealing condition color etched.

Table 1. Chemical Composition of DI used (Wt \%).

\begin{tabular}{|c|c|c|c|c|c|c|}
\hline $\mathrm{C}$ & $\mathrm{Si}$ & $\mathrm{Mn}$ & $\mathrm{S}$ & $\mathrm{P}$ & $\mathrm{Mg}$ & $\mathrm{Cu}$ \\
\hline 3.32 & 2.36 & 0.31 & 0.012 & 0.016 & 0.033 & 0.62 \\
\hline
\end{tabular}


Table 2. Metallographic characterization of as-cast samples (ASTM A 247).

\begin{tabular}{|c|c|c|}
\hline Nodule count $\left[\mathrm{nod} / \mathrm{mm}^{2}\right]$ & Nodularity [\%] & Nodule size \\
\hline 100 & $>95$ & 6 \\
\hline
\end{tabular}

\section{Methods}

\section{Determination of Elastic-plastic properties}

The Young moduli of the microsegregated zones were measured by means of microindentation tests using the Oliver and Pharr method [13]. The tests were performed using a T1900 SERIES Hysitron and a Vickers indenter. A load control method with a maximum load of $9500 \mu \mathrm{N}$ was used. The characterization of the yield stress ( $\sigma y s)$ and hardening coefficient (n) was performed by applying a modified version of an inverse analysis algorithm proposed in the literature [14]. The modified version uses inverse analyses of nano-indentation data ( $\mathrm{P}$ vs $\mathrm{h}$ ) and "pile-up" heights in combination with FE modelling of the indentation test.

The "pile-up" height was assessed by Atomic Force Microscopy (AFM) and the results were post-processed by means of Gwyddion ${ }^{\circledR}$ software. As an example, Fig. 2 shows the measurement of the indentation profile after nanoindentation test with Vickers indenter, and a 3D representation of the imprint as a result of the use of Gwyddion ${ }^{\circledR}$ software. The details of FE axisymmetric modelling of the indentation can be found in Fernandino [15]. A schematic representation of the methodology B is shown in Fig. 3.

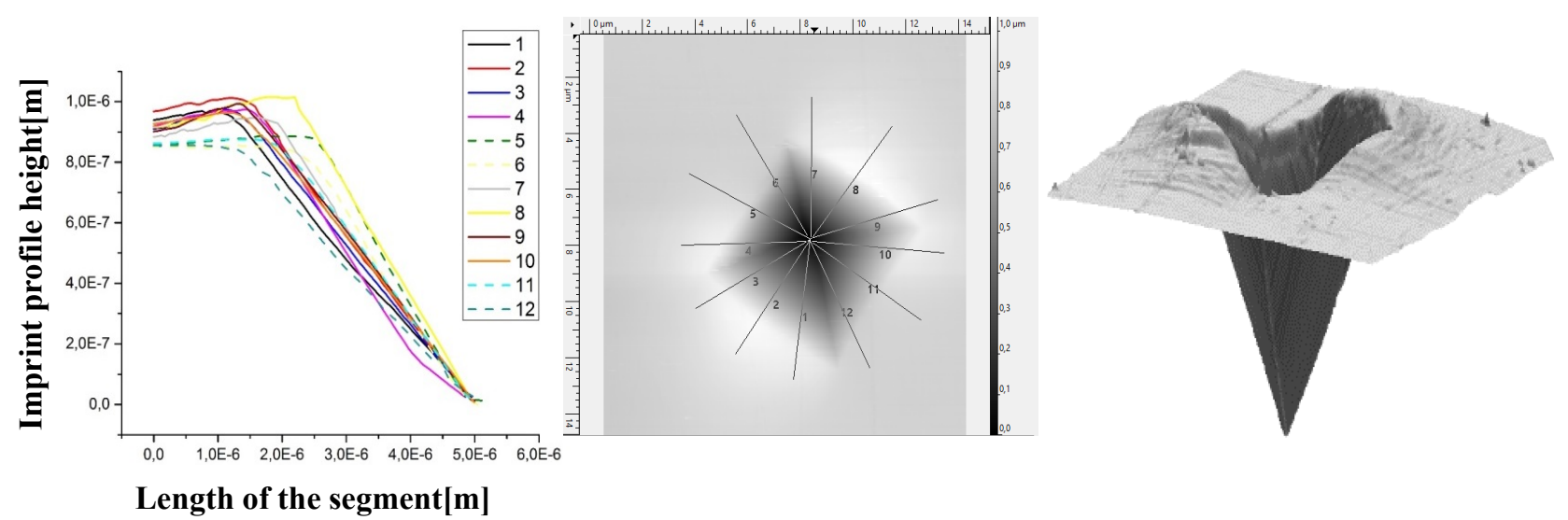

Figure 2. Imprint profile measure after nanoindentation test with Vickers indenter. Post-processing of the AFM data by means of Gwyddion ${ }^{\circledR}$ software.

\section{Micro-scale damage evolution}

The assessment of the micro-scale damage evolution was carried out by means of optical microscopy observations on very small-size double-notched tensile test specimens $(20 \mathrm{~mm} \times 2 \mathrm{~mm}$ $\mathrm{x} 1 \mathrm{~mm}$ ). The samples were tested under uniaxial loading and the microscopic observations were performed "in-situ" by adapting a Digital microscope camera Leyca MC120HD to a tensile test equipment specially designed for this purpose. Fig. 4a shows the experimental tensile test setup. Figure $4 \mathrm{~b}$, shows some of the micro-indentations imprints (Vickers indenter) performed in the sample before the test. Once the tensile test was concluded, the plastic strain suffered by the different zones of the microstructure was assessed by measuring the change in the distance between the adjacent imprints centers. 


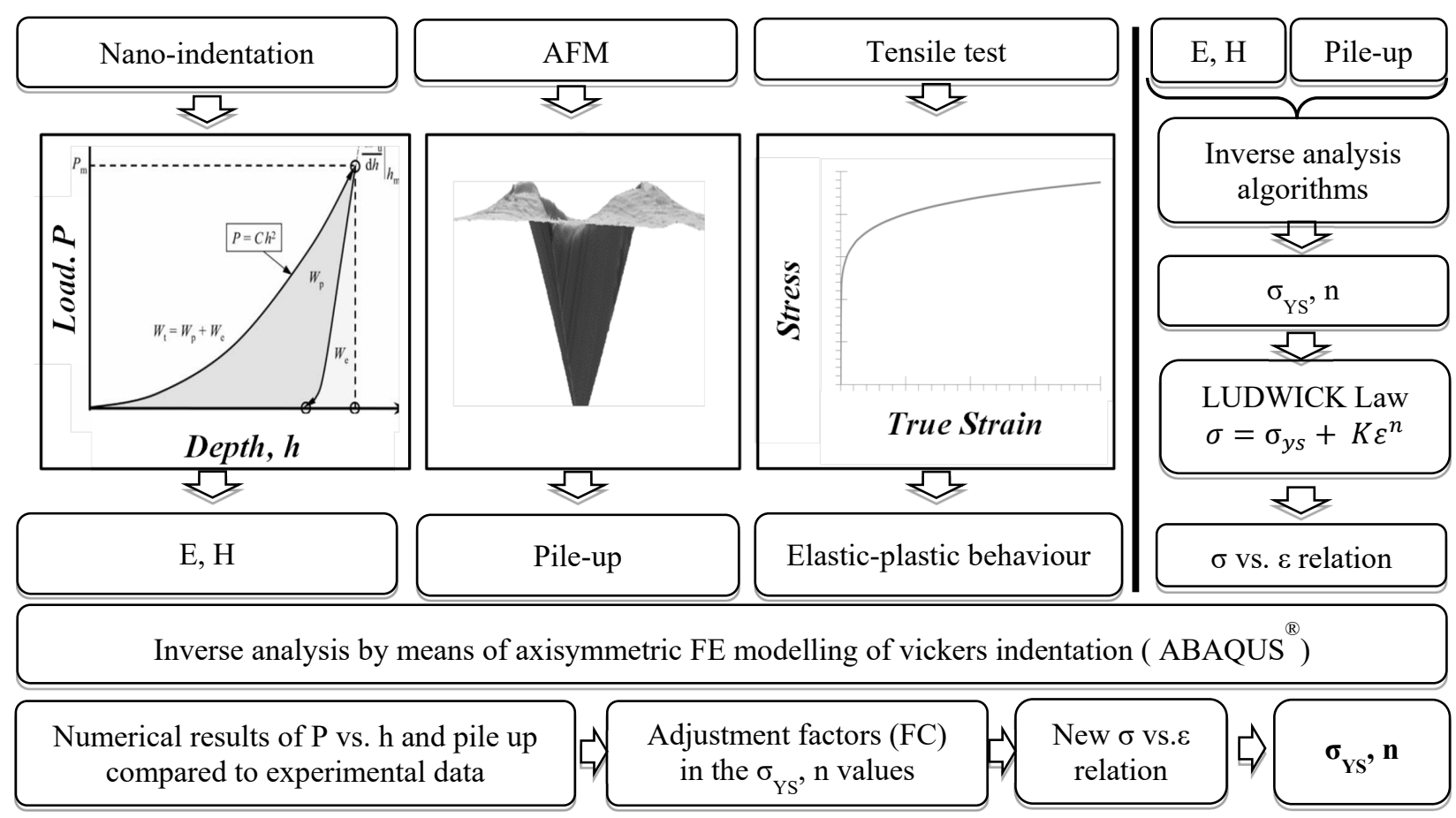

Figure 3. Schematic representation of the methodology B for determining the elastic-plastic properties of the microsegregated zones.

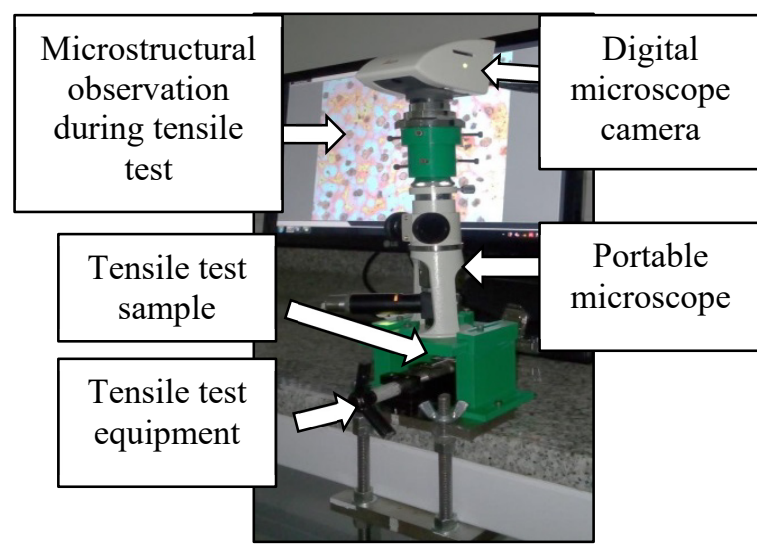

(a)

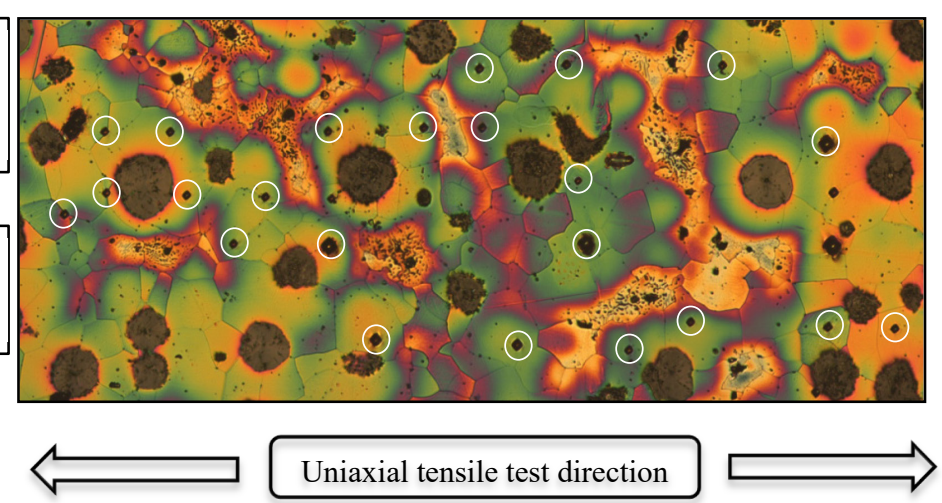

(b)

Figure 4. (a) Experimental "in situ" tensile test setup, (b) Some of the micro-indentation imprints used for the strain measurement.

\section{Results}

\section{Determination of Elastic-plastic properties}

The comparison between the experimental $\mathrm{P}$ vs $\mathrm{h}$ curves and the numerical results retrieved from FE indentation modelling by using the inverse analysis proposed by Mata et al (2013) and its modified version, are plotted in Fig. 5. Additionally, the numerical results of pile-up are plotted in Fig. 6. Fig. 5a shows the results of FTF zone. Note that the results retrieved from the methodology $\mathrm{B}$ are consistent with the experimental data, whereas the results using the inverse algorithms from literature underestimate the $\mathrm{P}$ vs $\mathrm{h}$ response. The same trend is observed for the numerical results of pile-up (see Fig.6a). For LTF zones, Fig. 5b, there is no significant change in the P vs h response, however, the numerical values of pile-up retrieved from FE models are noticeably different. The pile-up values obtained by applying the methodology B are consistent with the experimental data (see Fig.6b). The comparison between the experimental values of pile-up obtained from AFM and the numerical results from the inverse analysis are listed in Table 3. Additionally, note that the 
experimental results plotted in Fig. 5a and b show higher dispersion for LTF than for FTF, which is consistent with the heterogeneity characteristic of LTF zones (see Fig. 4b). This experimental dispersion of the results and its consequent dispersion of the values retrieved from the inverse algorithms proposed by Mata et al. [15], makes it necessary to specialize the analysis for cast iron samples, using the modified version previously described in the Methods section.

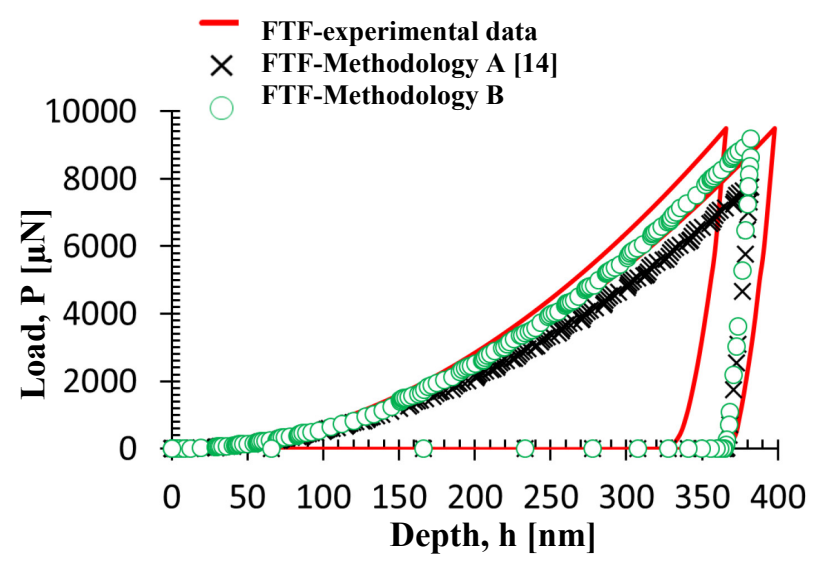

(a)

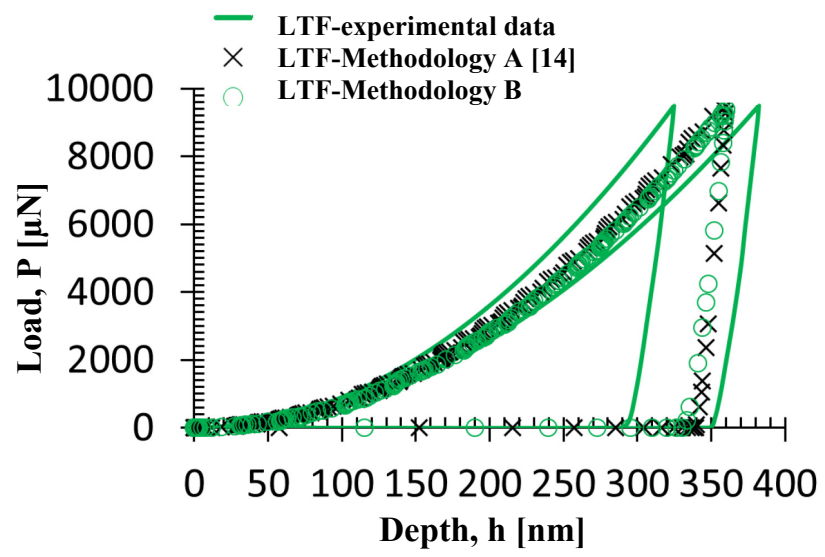

(b)

Figure 5. Comparison between the experimental $\mathrm{P}$ vs $\mathrm{h}$ data and the numerical results retrieved from FE indentation modelling, by using the inverse analysis proposed in the literature and its modified version. a) FTF zone, b) LTF zone.

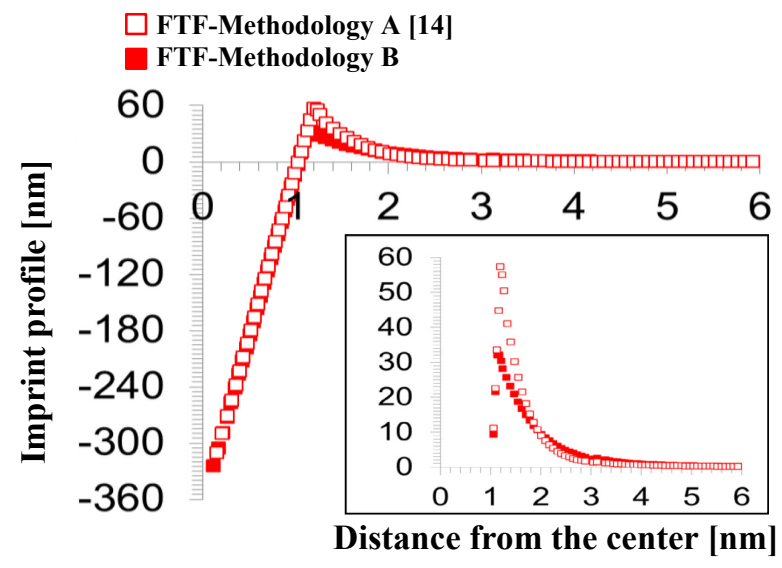

(a)

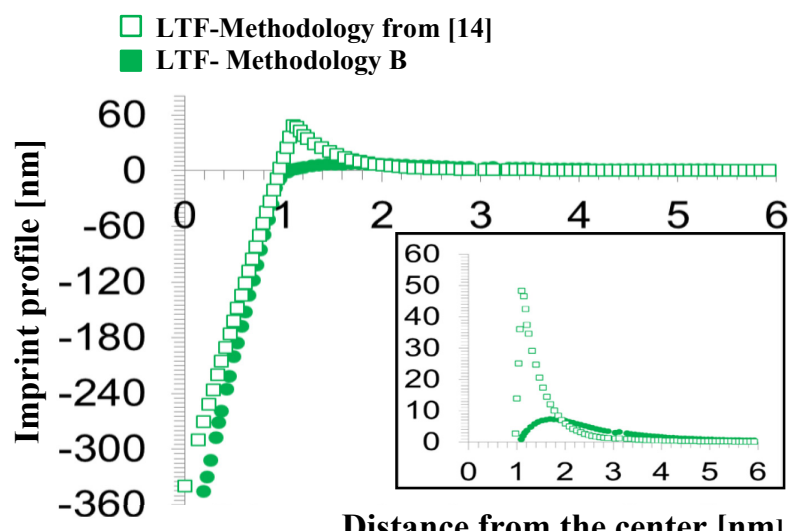

Distance from the center [nm]

(b)

Figure 6. Comparison between the numerical results of pile-up retrieved from FE indentation modelling, by using the methodology $\mathrm{A}^{[15]}$ and the methodology B. a) FTF zone, b) LTF zone.

Table 3. Result of elastic-plastic parameters obtained from the inverse methodology B.

\begin{tabular}{|c|c|c|c|}
\hline \multicolumn{2}{|c|}{ FTF zones } & \multicolumn{2}{c|}{ LTF zones } \\
\hline $\begin{array}{c}\text { Pile-up } \\
\text { (Experimental data) }\end{array}$ & $\begin{array}{c}\text { Pile-up } \\
\text { (Numerical data) }\end{array}$ & $\begin{array}{c}\text { Pile-up } \\
\text { (Experimental data) }\end{array}$ & $\begin{array}{c}\text { Pile-up } \\
\text { (Numerical data) }\end{array}$ \\
\hline $59 \pm 3 \mathrm{~nm}$ & $58 \mathrm{~nm}$ & $55 \pm 2 \mathrm{~nm}$ & $49 \mathrm{~nm}$ \\
\hline
\end{tabular}

Table 4 shows the elastic-plastic properties, E, $\sigma_{y s}$ and n, retrieved from the inverse analysis. E values of both FTF and LTF zones are similar enough to be assimilated to a single matrix material with its Young's modulus computed as the area-weighted average of the FTF and LTF elastic data, as reported by Fernandino et al [6]. However, clear differences in the plastic behavior are identified, where the LTF zones show higher strength. These differences could be associated to differences in chemical composition between LTF and FTF during the solidification process, particularly, the microsegregation of Si [3]. 
Table 4. Elastic-plastic parameters obtained from the inverse analysis.

\begin{tabular}{|c|c|c|c|c|c|}
\hline \multicolumn{3}{|c|}{ FTF zones } & \multicolumn{3}{c|}{ LTF zones } \\
\hline $\mathrm{E}[\mathrm{GPa}]$ & $\sigma_{\mathrm{ys}}[\mathrm{MPa}]$ & $\mathrm{n}$ & $\mathrm{E}[\mathrm{GPa}]$ & $\sigma_{\mathrm{ys}}[\mathrm{MPa}]$ & $\mathrm{n}$ \\
\hline $230 \pm 8$ & $300 \pm 10$ & $0.13 \pm 0.01$ & $255 \pm 7$ & $386 \pm 13$ & $0.14 \pm 0.01$ \\
\hline
\end{tabular}

\section{Micro-scale damage evolution}

A sequence of metallographies of the micro-scale damage evolution during in-situ tensile test is shown in Fig. 7. The white arrows indicate the initiation site of a crack whereas the gray arrows indicate the evolution of a crack previously observed at a lower load (the debonding of matrixnodule interface was not marked with these arrows). The results show crack nucleation and damage evolution preferentially located along the nodule-matrix interface (debonding mechanisms) and the FTF zones (plastic damage). Table 5 shows the results of micro-strain measurements of all fields analyzed. FTF zones show higher mean strain values than the LTF zones. These results verify that LTF zones show greater oys and n values than the FTF zones (see Table 4) and consequently, these zones are stronger. However, further investigations using Digital Image Correlation (DIC) are necessary to improve the accuracy of the measurements of the micro-strain fields and their correlation with the micro-segregated zones.

Table 5. Strain values obtained from the distance measurement between imprint centers.

\begin{tabular}{|c|c|c|c|}
\hline Zone & FTF & LTF & Macroscopic \\
\hline Strain [\%] & $13.4 \pm 2.9$ & $7.00 \pm 2.1$ & 11.3 \\
\hline
\end{tabular}

Micrographic observations allow distinguishing different stages during the fracture process.

i-The linear elastic stage, which encompasses macroscopic strains at which the graphite nodules remain bonded to the matrix;

ii-The early damage stage, which involves the gradual matrix-nodule decohesion and localization of plastic strain. As it is shown in Fig. 8a, matrix-nodule decohesion is observed as a clean and neat separation of the matrix-nodule interface. However, it is worth to mention that there are reports of more complex decohesion mechanisms in which nodules fail with an "onionlike" pattern [16].

iii- A ductile damage evolution stage. Once the matrix-nodule debonding is completed, the localized plastic strain is the driving mechanism for the development of ductile damage [17]. Fig. $8 \mathrm{~b}$ shows the plastic deformation bands typically located along internodular zones. Further load increments conduct to crack propagation of multiple cracks that eventually coalesce into a single dominant crack that leads to catastrophic material failure. Finally, Fig. 8c shows the optical micrography of the notched zone of the test sample before final fracture. It is worthy to note that there is a generalized damage of the microstructure and that the fracture energy not only is dissipated at the nucleation and propagation of the main crack but there is also a high level of energy dissipation involved in secondary cracks evolution which are mainly located at matrixnodule interface and FTF zones. 


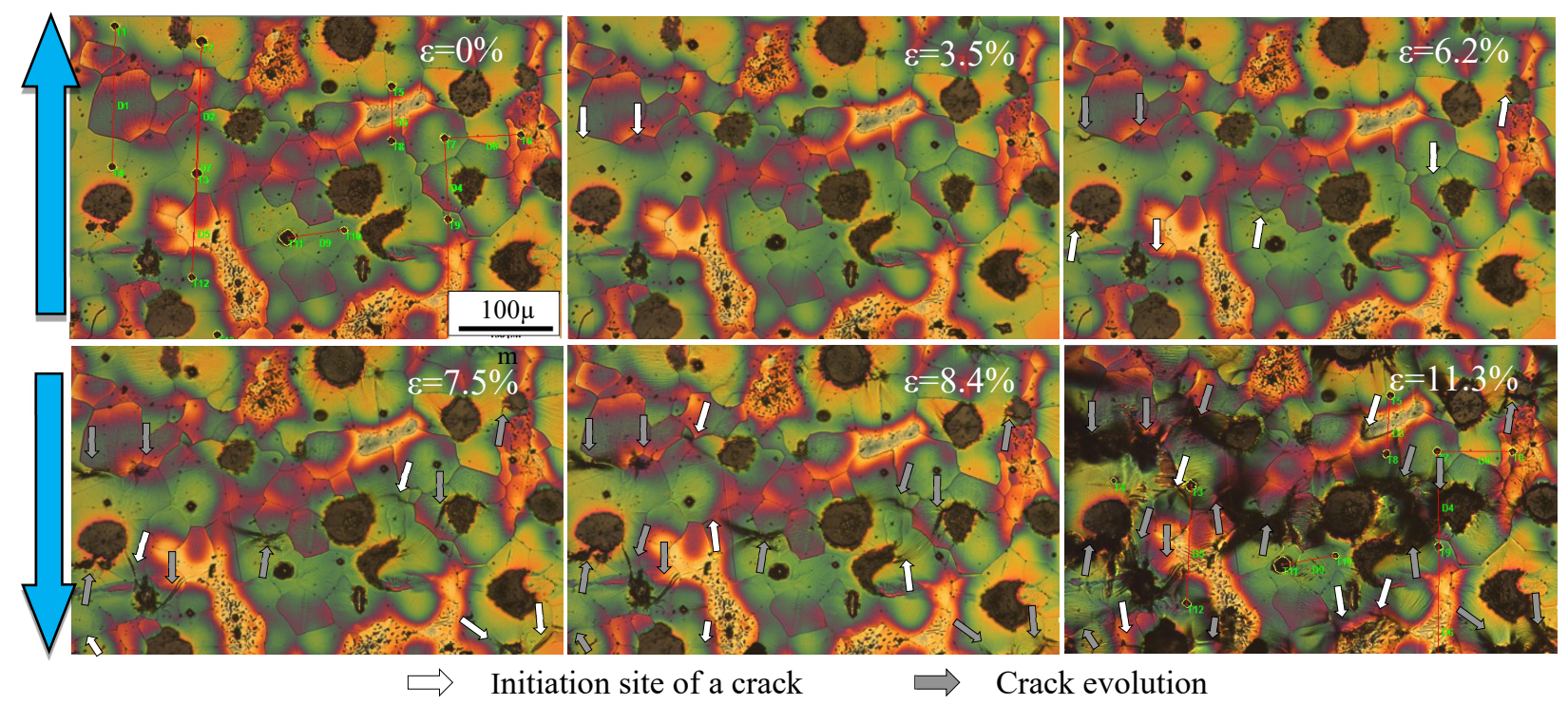

Figure 7. Metallographic observation of micro-scale damage evolution during in-situ tensile test. Loading in vertical direction.

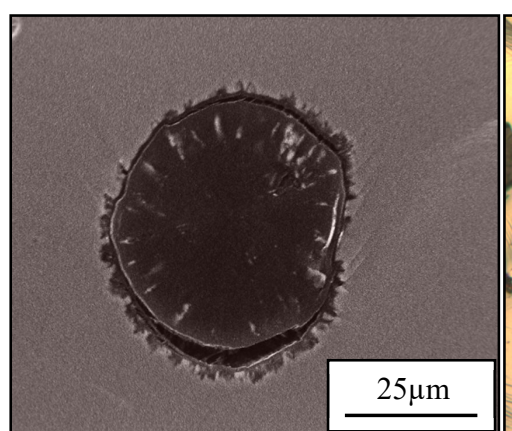

(a)

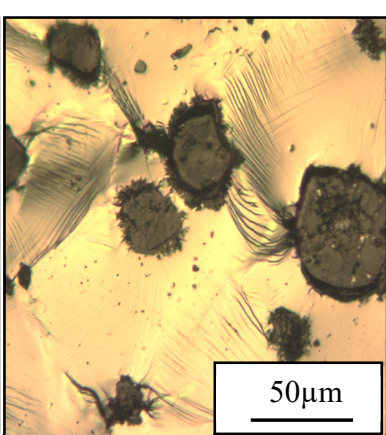

(b)

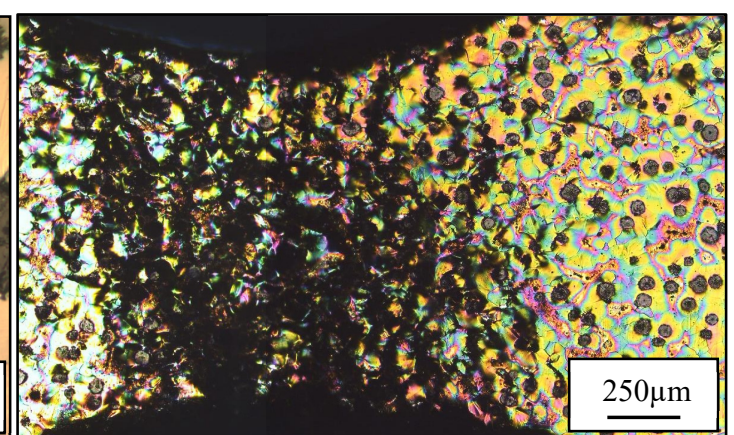

(c)

Figure 8. Metallographic observation from in situ tensile test. (a) SEM image. Clean and neat separation of the MNI, (b) optical micrography showing plastic deformation bands typically located in internodular zones, (c) optical micrography of the tensile test sample before the final fracture.

Loading in horizontal direction.

\section{Conclusions}

- The two zones differentiated on the FDI matrix, first-to-freeze zones and last-to-freeze zones, have similar elastic behaviors, and so can be assimilated to a single matrix material with its Young's modulus computed as the area-weighted average of the FTF and LTF elastic data.

- Clear differences in the plastic behavior of the first-to-freeze zones and the last-to-freeze zones are identified, where the LTF zones show higher strength values. Future analysis of damage micromechanisms should take into account these differences in the plastic behavior.

- The results of micro-scale damage analysis show crack nucleation and damage evolution preferentially along both the nodule-matrix interface (debonding mechanisms) and the FTF zones. From the micro-strain measurements it is observed that the FTF zones show higher strain values than the LTF zone. These results agree with the differences in mechanical properties measured experimentally. Further investigations using digital image correlation are necessary to improve the measurements of the micro-strain fields and the correlation with the micro-segregated zones.

- A generalized damage is observed along the sample before final fracture. These results allow to infer that a significant value of fracture energy is used in matrix-nodule debonding (early stage of damage) and, fundamentally, in the nucleation and propagation of secondary cracks that do not belong to the main fracture path (leading to the final fracture). 


\section{References}

[1] Ductile Iron Data for Design Engineers (1990). Cap. II Introduction.

[2] G. Rivera, R. Boeri, J. Sikora, Revealing and characterizing solidification structure of ductile cast iron. Material Science and technology. 18 (2002) 691-698.

[3] G. Rivera, R. Boeri, J. Sikora, Revealing the solidification structure of nodular iron. Int J Cast Metals Res. 8, 1 (1995) 1-5.

[4] N. Tenaglia, R. Boeri, G. Rivera, J. Massone, Study of shrinkage porosity in spheroidal graphite cast iron. Int J Cast Met Res. 29, 1-2, (2016) 112-120.

[5] R. Boeri, F. Weinberg, Microsegregation of alloying elements in cast iron. Cast metals, (1993) 153-158.

[6] D.O. Fernandino, A.P. Cisilino, R.E. Boeri, Determination of effective elastic properties of ferritic ductile cast iron by means computational homogenization and microindentation test. Mech Mater. 83 (2015) 110-121. doi:10.1016/j.mechmat.2015.01.002

[7] M. Dao, N. Chollacoop, K.J. Vanvliet, T. Venkatesh, Computational modeling of the forward and reverse problems in instrumented sharp indentation. Acta mater. 49 (2001) 3899-3918.

[8] M. Mata, J Alcalá, Mechanical property evaluation through sharp indentations in elastoplastic and fully plastic contact regimes. J Mater Res. 17 (2003) 1705-1709.

[9] O. Casals, J. Alcalá, The duality in mechanical property extractions from Vickers and Berkovich instrumented indentation experiments. Acta Mater. 53(2005) 3545-3561.

[10] H.Z. Lan, T.A. Venkatesh, On the uniqueness and sensitivity issues in determining the elastic and plastic properties of power-law hardening materials through sharp and spherical indentation. Philos. Mag. A. 87 (2007a) 4671-4729.

[11] H.Z. Lan, T.A. Venkatesh, On the sensitivity characteristics in the determination of the elastic and plastic properties of materials through multiple indentation. J. Mater. Res. 22 (2007b) 10431063.

[12] L. Liu, N. Ogasawara, N. Chiba, X. Chen, Can indentation technique measure unique elastoplastic properties? J. Mater. Res. 24 (2009) 784-800.

[13] W.C. Oliver, G.M. Pharr, An improved technique for determining hardness and elastic modulus using load and displacement sensing indentation experiments. J Mater Res. 7, 6 (1992) 1564-1583.

[14] M. Mata, J Alcalá , Mechanical property evaluation through sharp indentations in elastoplastic and fully plastic contact regimes. J Mater Res. 17 (2003) 1705-1709.

[15] D.O. Fernandino, Fracture of ductile cast iron. Experimental analysis and multi-scale modelling. PhD thesis, National University of Mar del Plata, March 2015. Mar del Plata, Buenos Aires, Argentina.

[16] V. Di Cocco, F. Iacoviello, A. Rossi, D. Iacoviello, Macro and microscopical approach to the damaging micromechanisms analysis in a ferritic ductile cast iron. Theor Appl Fract Mech. 69 (2014) 26-33. doi:10.1016/j.tafmec.2013.11.003

[17] K.A. Kasvayee, K. Salomonsson , E. Ghassemali, A.E.W. Jarfors, Microstructural strain distribution in ductile iron; comparison between finite element simulation and digital image correlation measurements. Mater Sci Eng A. 655 (2016) 27-35. doi:10.1016/j.msea.2015.12.056. 